\title{
Effects of Heat Treatment on Microstructures and Physical Properties of Segmented Thermal Barrier Coatings
}

\author{
Hongbo Guo*, Hideyuki Murakami and Seiji Kuroda \\ Materials Engineering Laboratory, National Institute for Materials Science, \\ 1-2-1 Sengen, Tsukuba Science City, Ibaraki 305-0047, Japan
}

Highly segmented thermal barrier coatings (TBCs) were produced by "hot" plasma spraying. The effects of heat treatment on the microstructures, mechanical and thermophysical properties were studied. The segmented coatings are denser than traditionally plasma-sprayed TBCs due to its good insplat bonding at high substrate temperature. The segmentation cracks and associating branching cracks hardly propagated or closed during sintering process, indicative of a good stability of crack network. Due to its low porosity, the segmented coatings compromised the property of thermal insulation of TBCs. For the coatings after $24 \mathrm{~h}$ heat treatment at $1523 \mathrm{~K}$, the thermal conductivity was improved by around $35 \%$. The segmentation cracks had a strong impact on decreasing the Young's modulus. Heat treatment could not effectively promote the increase of the Young's modulus, especially for the case of highly segmented coatings.

(Received April 25, 2005; Accepted June 27, 2005; Published August 15, 2005)

Keywords: thermal barrier coatings, plasma spraying, sintering, segmentation cracks, microstructure, thermal conductivity, Young's modulus

\section{Introduction}

Thermal barrier coatings (TBCs) are used in hot path components of gas turbines (typically combustion chambers, transition pieces, turbine blades and vanes) to protect the components against hot gases. A typical plasma sprayed TBC system consists of a low pressure plasma sprayed (LPPS) MCrAlY bond coat which protects the underlying substrate from oxidation and corrosion and atmospheric plasma sprayed $\mathrm{ZrO}_{2}-7-8$ mass $\% \mathrm{Y}_{2} \mathrm{O}_{3}$ topcoat which works as a thermal insulation layer.

Premature spallation-failure of TBCs during high temperature exposure often occurs. In plasma sprayed TBCs, the failure occurs by cracking at the interface between the bond coat and the thermally grown oxide (TGO) layer or at the topcoat splat boundaries. ${ }^{1-3)}$ For rather thin TBCs (less than $0.5 \mathrm{~mm}$ in topcoat thickness) the high durability of the coatings can be achieved by the utilization of porous, microcracked structures. ${ }^{4,5}$ For thick TBCs different microstructures have been tested, e.g. coatings with a high level of porosity. ${ }^{4)}$ A successful method is the introduction of segmentation cracks into the coating. ${ }^{6,7)}$ Such kind of cracks can greatly improve the compliance of coatings to the substrate. Segmented TBCs have been produced by "hot" spraying (high heat input to substrate and no cooling during spraying). Due to the special spray processing, the microstructures of the segmented coatings are quite different from those of traditionally sprayed coatings. It is certain that the properties of the segmented coatings will accordingly differ from those of the traditional coatings. However, few papers have been published in regard to the mechanical and thermophysical properties of the segmented TBCs.

Operation at high temperature could sinter TBC materials, i.e. microcracks and pores are closed or at least reduced in surface area. The sintering effect is disadvantageous to TBCs because it will increase thermal conductivity ${ }^{8)}$ and Young's modulus of the coatings ${ }^{9)}$ and will reduce thermal shock resistance. ${ }^{10)}$ In order to fully make use of the potential

*Corresponding author, E-mail: guo.hongbo@nims.go.jp advantages of the segmented TBCs, it is necessary to understand the effects of sintering on the microstructures and resultant properties of the coatings.

In this paper, yttria stabilized zirconia coatings with different segmentation crack density are produced by varying spray processing parameters. The elastic property and thermal conductivity of the coatings are concerned. Also, the effects of heat treatment on the microstructures and properties are studied.

\section{Experimental}

Commercial $\mathrm{ZrO}_{2}-8$ mass $\% \mathrm{Y}_{2} \mathrm{O}_{3}$ powder feedstock (K90, Showa Denko), featured as fused $\&$ crashed, is chosen as spraying materials for YSZ coatings. YSZ coatings have been sprayed onto substrates in atmospheric plasma spraying equipment using an SG 100 gun (Praxair, USA). Three sets of spray parameters were used aiming at achieving different segmentation crack densities within the coatings, as shown in Table 1. The choice of spray parameters is based on our previous work. ${ }^{11)}$ Typically, three substrate temperatures, 773, 923 and $1073 \mathrm{~K}$, were obtained. No air cooling was applied during the spraying.

Optical microscopy (OM) and scanning electron microscopy (SEM) were used to characterize the microstructures of the sprayed coatings. Segmentation cracks are defined as the cracks running perpendicular to the coating surface and penetrating at least half the coating thickness. Segmentation crack densities $\left(D_{\mathrm{s}}\right)$ were calculated by dividing the number of such cracks in a cross section with the horizontal length of

Table 1 The spraying parameters used for YSZ coatings.

\begin{tabular}{lccc}
\hline \multicolumn{1}{c}{ Parameters } & C1 & C2 & C3 \\
\hline Power (kW) & 32 & 30 & 38.4 \\
Ar flow rate (slpm) & 50 & 50 & 50 \\
He flow rate (slpm) & 27 & 27 & 27 \\
Powder feed rate (g/min) & 20 & 20 & 20 \\
Spray distance (mm) & 100 & 80 & 60 \\
Substrate temperature (K) & 773 & 923 & 1073 \\
\hline
\end{tabular}


the cross section. Branching cracks are cracks parallel to the coating plane, starting from the segmentation cracks. Free standing coating specimens were produced by removing substrates from coatings with hydrochloric acid solution. Heat treatment of the free standing specimens was performed at $1523 \mathrm{~K}$ in air furnace. Bulk densities $(\rho)$ and porosity of the specimens were measured by Archimedes's technique.

Thermal diffusivities $\alpha(T)$ were determined by a laser flash diffusivity apparatus (ULVAC, TC-7000). Specific heats $C_{p}(T)$ were measured using a differential scanning calorimeter (Netzsch, STA 449C). Thermal conductivities $K(T)$ were calculated using the following equation:

$$
K(T)=\alpha(T) \times C_{p}(T) \times \rho .
$$

Young's modulus $E$ measurements of the free-standing specimens were carried out by using a flexural resonance tester (Nippon Techno-Plus Co. Ltd., JE-RT3).

\section{Results and Discussion}

Figure 1 shows the optical micrographs of the crosssections of the $8 \mathrm{YSZ}$ coating deposited at $1073 \mathrm{~K}$ before and after $24 \mathrm{~h}$ heat treatment at $1523 \mathrm{~K}$. Segmentation cracks, running perpendicular to the coating surfaces, are present in the coatings. However, the segmentation cracks can not be easily identified in the as-sprayed coating at low magnification. The reason for this phenomenon is that segmentation cracks are somewhat closed due to the residual stresses developed in the coating since the coating is attached to the
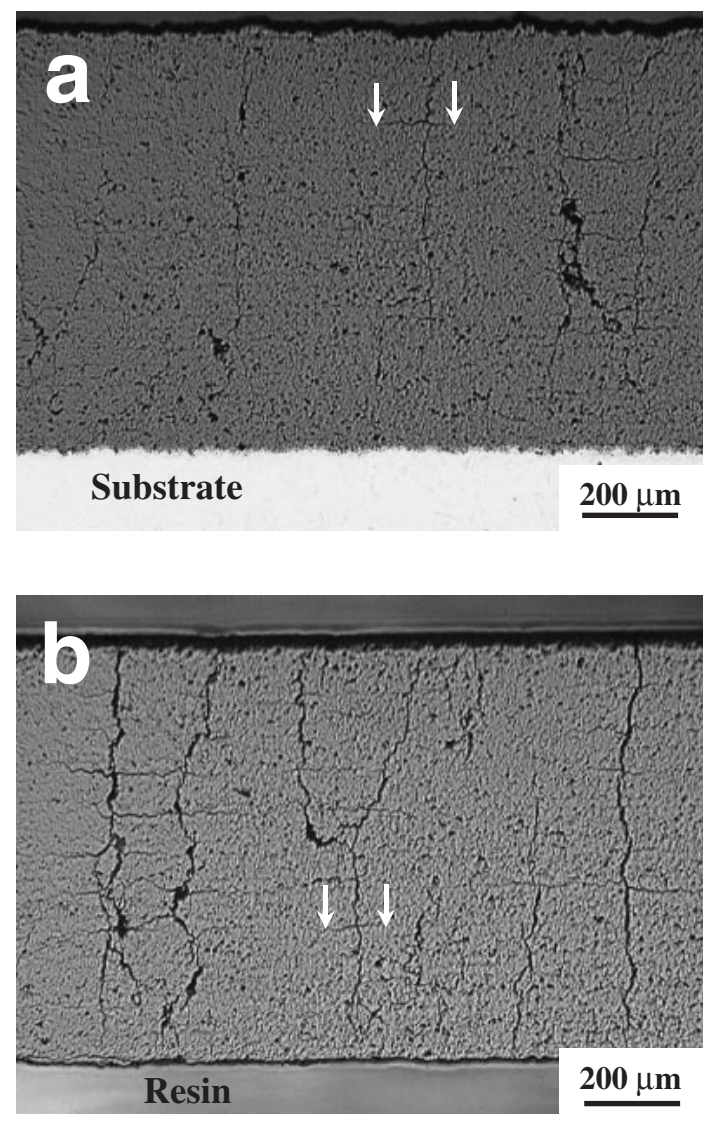

Fig. 1 Optical micrograph of cross-section of 8 YSZ coating sprayed at $1073 \mathrm{~K}$. (a) as-sprayed with substrate; (b) after $24 \mathrm{~h}$ heat treatment at $1523 \mathrm{~K}$ without substrate. substrate. In contrast to this, the cracks presenting in the frees-standing coating are more visible due to the release of residual stresses. Some branching cracks, as indicated by the white arrows in Fig. 1, are also present together with the segmentation cracks. Few interlamellar delaminations and large pores are visible, indicative of a high density of the coating. Sintering process usually causes closure and rounding of cracks. However, a significant difference can not be observed in the coating after heat treatment.

Figure 2 shows the fracture surfaces of cross-sections of the above coatings, which reveal the splat-splat interactions during deposition and columnar grains in each splat are evident. Within the lamella, most of splat boundaries were eliminated and some columnar grains even went through the whole lamella. In the case of high particle and substrate temperature, the heat from the recently sprayed splats could be high enough to cause the surface remelting of the underlying splat (or the underlying splat was still in the liquid state) when the recently splats impinged on the surface of the underlying splat. Thus, solidification of the liquid splats will start at the interface to the underlying splat and proceed towards the heat flow. Therefore, after finishing a lamella, it contains columnar grains through the lamella thickness. And, most of the intersplat boundaries in the lamella are eliminated. It is disclosed that a good intersplat bonding is the crucial factor for the development of segmentation cracks. ${ }^{7,11)}$ The coating after heat treatment reveals rounding of originally sharp edges, as shown in Fig. 2(b). Besides, Heat treatment resulted in grain growth and bridging interfaces between splats in close physical
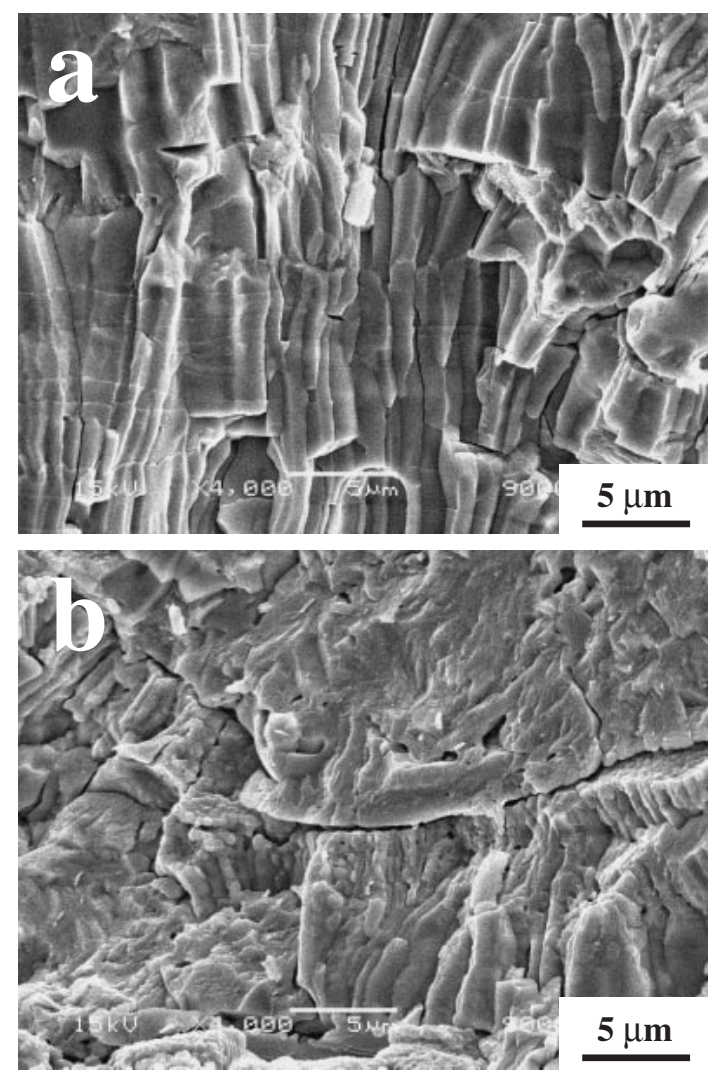

Fig. 2 SEM micrographs of fracture surfaces of cross-sections of $8 Y S Z$ coatings sprayed at $1073 \mathrm{~K}$. (a) as-sprayed, (b) $24 \mathrm{~h}$ heat treatment at $1523 \mathrm{~K}$. 


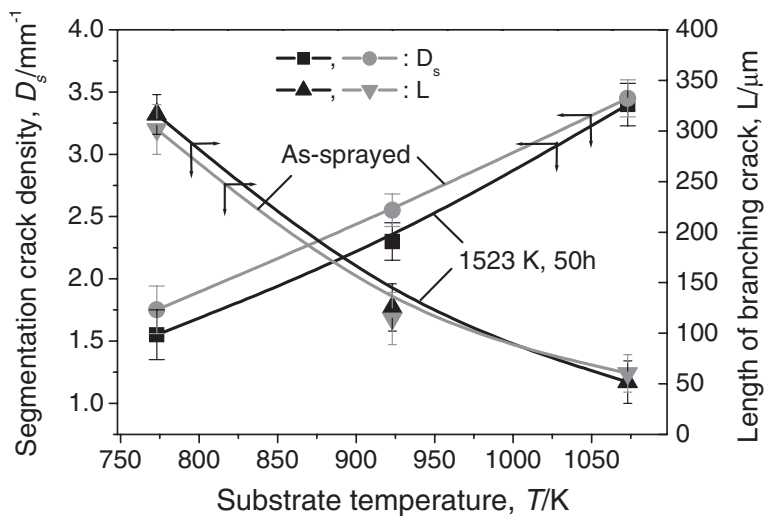

Fig. 3 Measured segmentation crack density and length of branching cracks on frees-standing coating specimens.

proximity. There is also evidence of the healing of throughthickness microcracks.

Measurements of segmentation crack density $\left(D_{\mathrm{s}}\right)$ and average length of branching cracks (horizontal distance between the white arrows as shown in Fig. 1) were performed on the free-standing specimens. Increasing substrate temperatures $\left(T_{\mathrm{s}}\right)$ has a substantial effect on increasing the $D_{\mathrm{s}}$, as shown in Fig. 3. Typically, the $D_{\mathrm{s}}$ of the coatings deposited at $1073 \mathrm{~K}$ is higher than $3 \mathrm{~mm}^{-1}$. As discussed earlier, a good splat bonding achieved at high $T_{\mathrm{s}}$ promotes the propagation of segmentation cracks. The coatings after heat treatment reveal slight difference in the $D_{\mathrm{s}}$ compared with the coatings before heat treatment; however, the difference can be neglected in regard to the measurement errors. On the other hand, for the coatings deposited at higher $T_{\mathrm{s}}$, the branching cracks is apparently shorter than those in the coatings deposited at lower $T_{\mathrm{s}}$, probably due to the better interlamellar bonding at high $T_{\mathrm{s}}$. In addition, there is little change in the length of the cracks even after $50 \mathrm{~h}$ heat treatment. Therefore, it can be concluded that the segmentation cracks and branching cracks hardly propagated and closed during sintering.

Figure 4 shows the porosity of the free-standing specimens determined by Archimedes's technique. The porosity of the coatings is in a range of $9-11 \%$, which is relatively lower than those of the traditionally sprayed coatings (the porosity of traditional TBCs is usually higher than 12\%). The lower porosity of the segmented coatings was mainly due to the decreased volume of micropores which is attributed to the elimination of splat boundaries within a lamella. ${ }^{11)}$ The heattreated coatings reveal a slightly decreased porosity due to the sintering process. Sintering process of TBC materials consists of two separate phases. The first, mainly occurring at very early stage $(<10 \mathrm{~h})$, is characterized by the improvement of intersplat bonding attributed to microcrack healing and by the trans-splat grain growth. The latter sintering quasistationary stage promotes mainly the change of pore shape and the reduction of macro-pore volumes. In particular, phenomena involved in microcrack healing and shape changes are reported to take place at temperatures as low as $1173 \mathrm{~K}$, while pore system can be affected by sintering only at temperatures above $1473 \mathrm{~K}$.

The measured thermal diffusivities of the free-standing YSZ coating specimens are shown in Fig. 5(a), which are

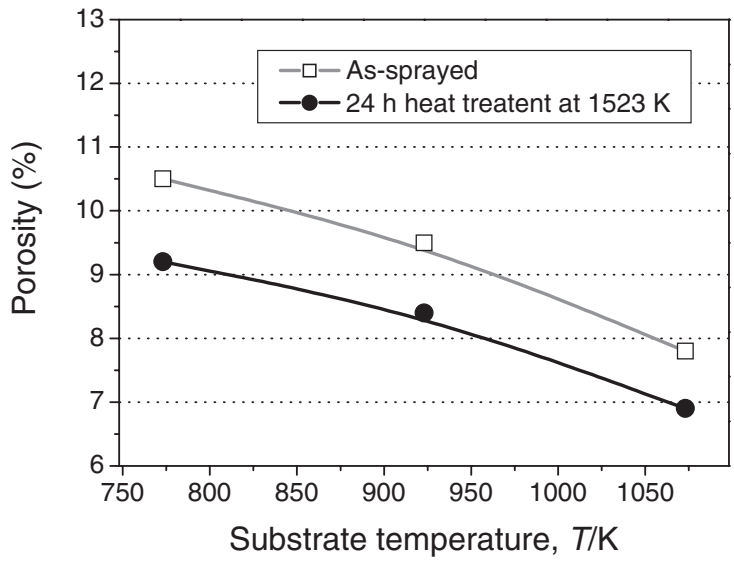

Fig. 4 Porosity of free-standing YSZ coating specimens determined by Archimedes's technique.
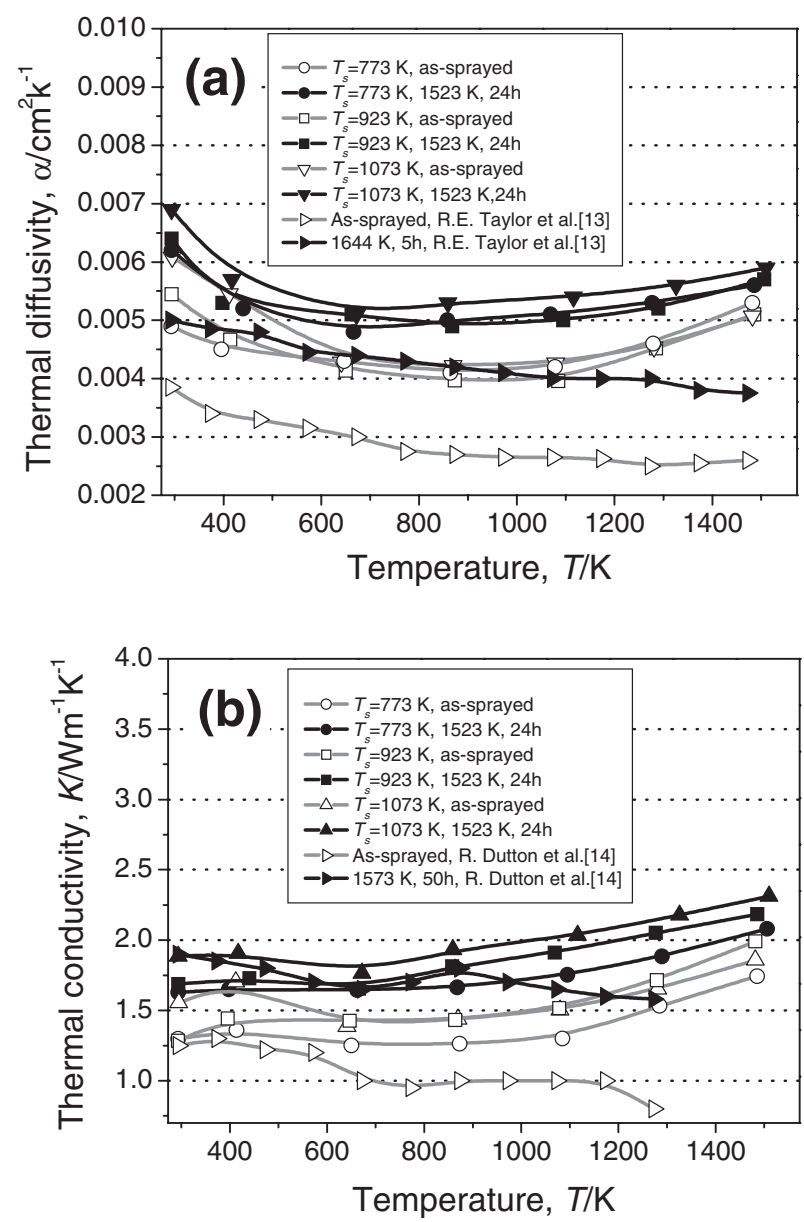

Fig. 5 Thermal diffusivities (a) and thermal conductivities (b) of 8 YSZ coatings.

rather temperature dependant. The sprayed coatings reveal a similar diffusivity of $0.0045 \mathrm{~cm}^{2} / \mathrm{K}$ at $1273 \mathrm{~K}$, which is apparently higher than the values of diffusivities of traditional coatings. ${ }^{12)}$ For the coatings after $24 \mathrm{~h}$ heat treatment, the diffusivity was increased. Specifically, the diffusivity of the coating deposited at $1073 \mathrm{~K}$ was increased up to $0.0055 \mathrm{~cm}^{2} / \mathrm{k}$. The calculated thermal conductivity from the eq. (1) is shown in Fig. 5(b). Compared with traditional 8 YSZ coatings, the segmented coatings show a significant improvement in the conductivity. ${ }^{13)}$ This indicates that the 


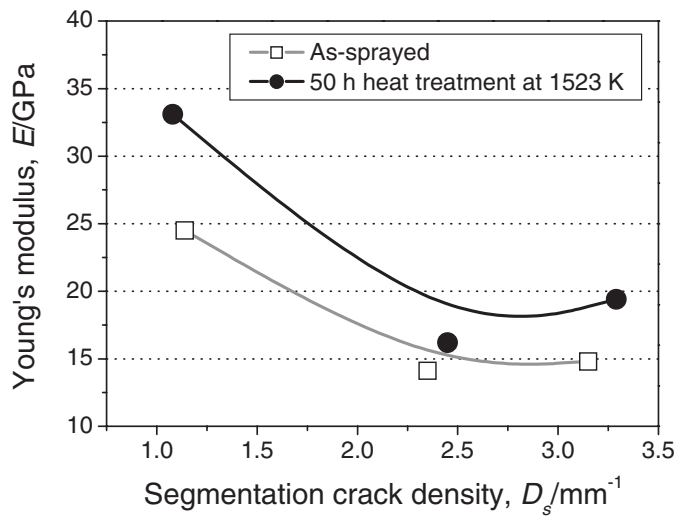

Fig. 6 Dependence of Young's modulus on segmentation crack density of 8 YSZ coatings.

segmented TBCs compromise the property of thermal insulation of TBCs. Sintering process caused an apparent increase of the conductivity. For the coating deposited at $1073 \mathrm{~K}$, the conductivity at $1273 \mathrm{~K}$ is improved by around $35 \%$. Some irreversible microstructure change took place during high temperature exposure. ${ }^{8,14)}$ In particular, reduction of the crack-like micro-porosity has been observed due to the densification processes, typically caused by sintering. These could be considered as the main mechanisms responsible for the increase of thermal conductivity. Moreover, for the thick TBC another possible contribution to the increase of thermal conductivity could be ascribed to changes of the pore structure caused by the residual stress relaxation at high temperature as reported by Schwingel et al. ${ }^{15)}$

The Young's modulus of the free standing specimens was determined by flexural resonance. Figure 6 shows the dependence of the Young's modulus on segmentation crack density $\left(D_{\mathrm{s}}\right)$. For the coating with low $D_{\mathrm{s}}$, the Young's modulus is around $25 \mathrm{GPa}$, whereas it decreases to $15 \mathrm{GPa}$ with increasing the $D_{\mathrm{s}}$ from 1.2 to $3.2 \mathrm{~mm}^{-1}$. This indicates that the segmentation cracks have a strong impact on decreasing the Young's modulus. After $50 \mathrm{~h}$ heat treatment, the coating with low $D_{\mathrm{s}}$ shows a little increase of the Young's modulus, due to the stiffening of the coating. However, for the highly segmented coatings, the increase is very limited. This means sintering process could not effectively promote the increase of the Young's modulus. The Young's modulus of plasma sprayed YSZ coatings ranges from 5 up to 100 $\mathrm{GPa}$. The broad range of values is explained by the variable and anisotropic microstructure of the coatings. In addition, the measurement technique may affect the results. Literatures report that a sintering process often results in a significant increase of the Young's modulus of traditionally sprayed YSZ coatings. ${ }^{16)}$ For the case of the segmented coatings, the situation is different because the segmentation cracks play a dominate role in determining the modulus of the coatings.

In general, heat treatment of TBCs usually increased the Young's modulus and thermal conductivity due to sintering processing. ${ }^{9)}$ Higher porosity level (for the case of traditional TBCs) led to a significant increase in the sintering rate of the coating during high temperature annealing. ${ }^{17)}$ The sintering effect is disadvantage, because it will degrade the thermal insulation and reduce thermal shock resistance. ${ }^{16)}$ In the present study, the highly segmented coatings are extremely dense due to the "hot" plasma spraying condition. As a result, the amount of sintering and shrinkage during high temperature treatment was greatly reduced. As low sintering rates are essential for a good high-temperature capability, the segmented coatings are expected to be promising in improving performance of TBC system.

\section{Conclusions}

Highly segmented thermal barrier coatings were produced by "hot" plasma spraying fused \& crashed powders. Due to the improved contact between splats, the sprayed coatings revealed lower porosity than traditionally sprayed coatings. The segmentation cracks and associated branching cracks hardly propagated or closed during heat treatment. Due to its low porosity, the segmented coatings compromised the property of thermal insulation of TBCs. For the coatings after $24 \mathrm{~h}$ heat treatment at $1523 \mathrm{~K}$, the conductivity was improved by around $35 \%$. The segmentation cracks have a strong impact on decreasing the Young' modulus of TBCs. Sintering processes could not effectively promote the increase of Young's modulus, especially for the highly segmented coatings.

\section{Acknowledgements}

This work is supported by JSPS Fellowship program. Dr. Isoda from National Institute for Materials Science (NIMS), and Dr. Sodeoka from National Institute of Advanced Industrial Science and Technology (AIST) are gratefully acknowledged for their contributions in experiments.

\section{REFERENCES}

1) R. A. Miller and C. E. Lowell: Thin Solid Films 95 (1982) 265-273.

2) A. Rabiei and A. G. Evans: Acta Mater. 48 (2000) 3963-3976.

3) K. W. Schlichting, N. P. Pature, E. H. Jordan and M. Gell: Mater. Sci. Eng. A 342 (2003) 120-130.

4) H.-D. Steffens, Z. Babiak and M. Gramlich: J. Therm. Spray Technol. 8 (1999) 517-522.

5) D. Zhu and R. A. Miller: Mater. Sci. Eng. A 245 (1998) 212-223.

6) P. Bengtsson, T. Ericsson and J. Wigren: J. Therm. Spray Technol. 7 (1998) 340-348.

7) H. B. Guo, R. Vaßen and D. Stöver: Surf. Coat. Technol. 186 (2004) 353-363.

8) F. Cernuschi, L. Lorenzoni, S. Ahmaniemi, P. Vuoristo and T. Mäntyla: J. Eur. Ceram. Soc. 25 (2005) 393-400.

9) M. Ahrens, S. Lampenscherf, R. Vaßen and D. Stöver: J. Therm. Spray Technol. 13 (2004) 432-442.

10) D. Zhu and R. A. Miller: Surf. Coat. Technol. 108 (1998) 114-120.

11) H. B. Guo, S. Kuroda and H. Murakami: Thin Solid Films (2005) in press.

12) S. Ahmaniemi, P. Vuoristo, T. Mäntylä, F. Cernuschi and L. Lorenzoni: J. Eur. Ceram. Soc. 24 (2004) 2669-2679.

13) R. E. Taylor, X. Wang and X. Xu: Surf. Coat. Technol. 120-121 (1999) 89-95.

14) R. Dutton, R. Wheeler, K. S. Ravichandran and K. An: J. Therm. Spray Technol. 9 (2000) 204-209.

15) D. Schwingel, C. Persson, R. Taylor, T. Johannesson and J. Wigren: High Temp.-High Press 27-28 (1995-1996) 273-282.

16) D. Basu, C. Funk and R. W. Steinbrech: J. Mater. Res. 14 (1999) 4643 4650 .

17) R. Vaßen, N. Czech, W. Malléner, W. Stamm and D. Stöver: Surf. Coat. Technol. 161 (2002) 26-35. 